\title{
Editorial
}

\section{Indocyanine Green Videoangiography in Aneurysm Surgery}

\author{
Abrar Ahad Wani ${ }^{1}$ Mohsin Bhat ${ }^{1}$ \\ ${ }^{1}$ Department of Neurosurgery, Sheri-Kashmir Institute of Medical \\ Sciences, Srinagar, Jammu and Kashmir, India
}

Indian J Neurosurg:2020;9:141-142

Aneurysmal subarachnoid hemorrhage (SAH) is still a worldwide health problem despite innovations in the microsurgical and endovascular procedures. Ruptured cerebral aneurysm account for 75 to $85 \%$ of SAH in nontraumatic cases. ${ }^{1}$ The goal of intervention is complete aneurysmal obliteration with the preservation of the parent, perforating, and branching vessels. The outcome of aneurysmal surgery has to be balanced between the failure to achieve complete aneurysmal closure resulting in regrowth and hemorrhage ${ }^{2}$ and inadvertent occlusion of the surroundings vessels by the clip causing cerebral infarction. This can result in a significant increase in the morbidity and mortality rates. Therefore, optimum clip placement in situ is essential to achieve the desired outcome, ${ }^{3}$ and for this indocyanine green (ICG) is very helpful ( - Figs. $\mathbf{1}$ and $\mathbf{2}$ ).

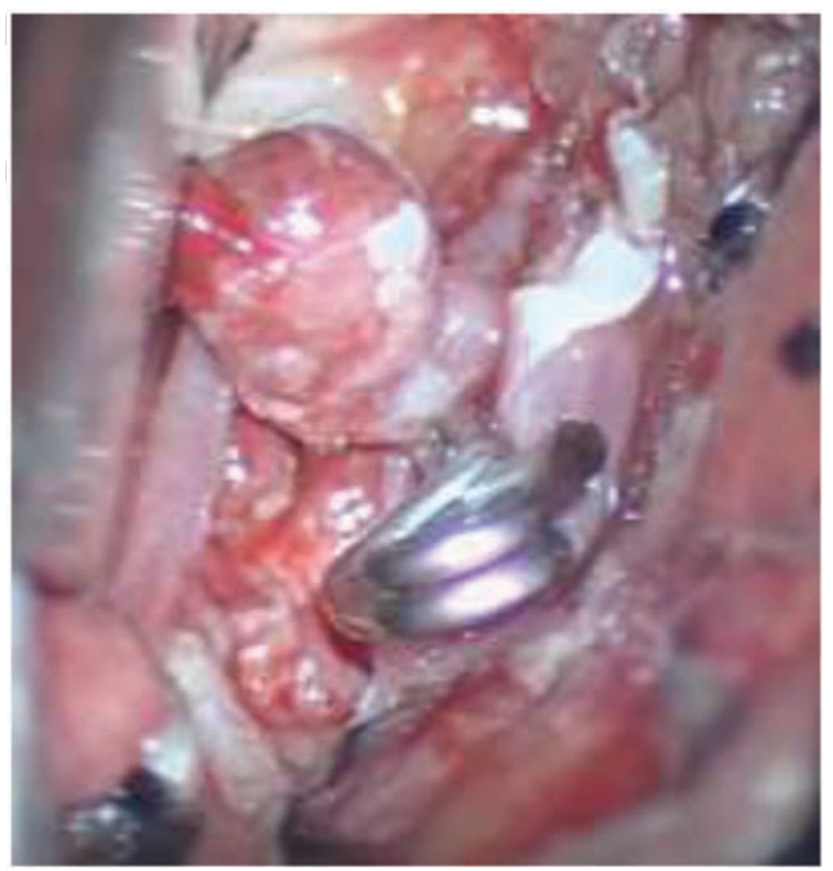

Fig. 1 Intraoperative picture showing clipped distal anterior cerebral artery aneurysm.

Address for correspondence Abrar Ahad Wani, MCh, Department of Neurosurgery, Sher-i-Kashmir Institute of Medical Sciences, Soura, Srinagar 190011, Jammu and Kashmir, India (e-mail: drabrarahadwani@gmail.com).
Recently, Rabb at al ${ }^{4}$ revived the technique of intraoperative fluorescence angiography and used a novel technique of using the fluorescence dye ICG to visualize the basal cerebral arteries to assess the vessel anatomy. ICG, being an inert agent, does not cause any contrast reactions. ${ }^{7}$ ICG video angiography (ICG-VA) has a good safety profile, is easy to use, and discerns the anatomy of the cerebral circulation within 2 to 3 minutes, thus promises to fulfill the prerequisite of the aneurysmal surgery. ICG-VA provide real-time, highly special resolved image of the intraoperative vasculature confirming the position of the clip immediately, and facilitates any intraoperative adjustment if necessary. ${ }^{2,5-7}$

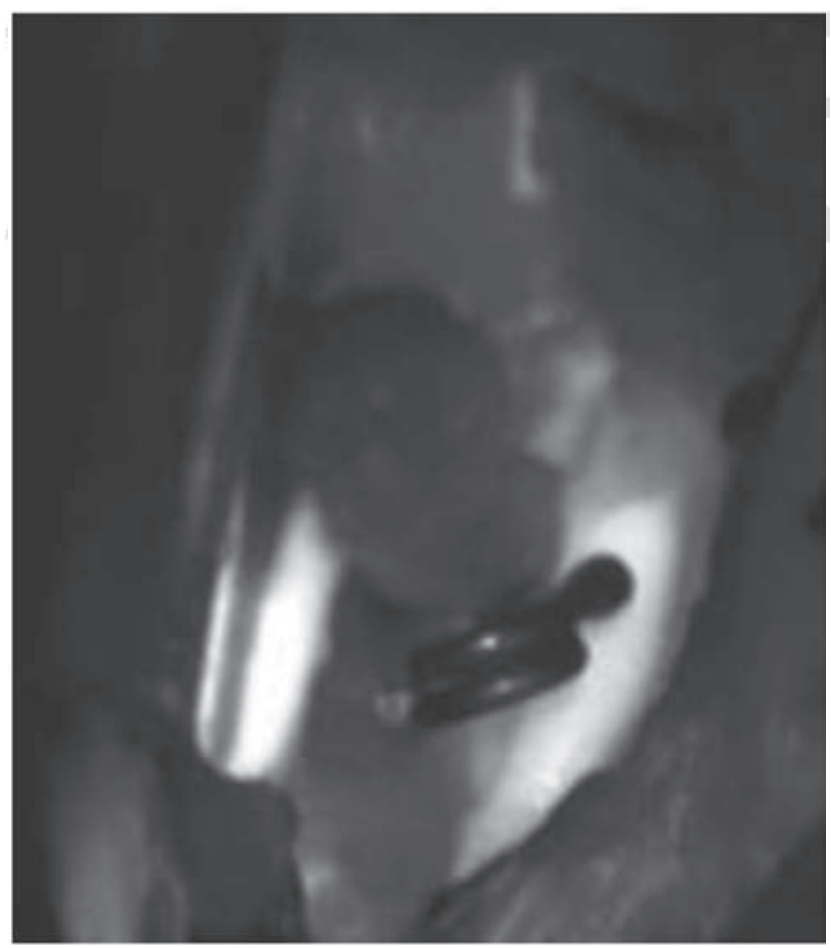

Fig. 2 ICG-VA showing aneurysm being obliterated and all major vessels in vicinity having good blood flow. ICG-VA, indocyanine green videoangiography.
DOI https://doi.org/ 10.1055/s-0040-1709223 ISSN 2277-954X. 
Several studies show the reliability and accuracy of the ICG. The short performance time, a low cost, and very low complication rate makes it a feasible option in developing countries. Repetitive assessment during surgery enabling the clip replacement within the ischemic threshold time is an added advantage. There is only short interruption in surgical procedure. In $10 \%$ of the cases, small aneurysmal sac can be overlooked intraoperatively by ICG-VA; however, these small residual aneurysms may or may not have serious consequences. ${ }^{6}$

However, there are some studies demonstrating poor correlation between ICG angiography and intraoperative/ postoperative digital subtraction angiography (DSA). In a large meta-analysis, the rate of misclippings that were not identified on microscopic visual observation and were identified at ICG-VA was $6.1 \%$, while the rate of misclippings that were not identified on ICG-VA and were identified at postoperative DSA was $4.5 \%$. This may have clinical implications and may alter the decision to retreat residual aneurysmal sacs. So the authors recommend a combination of intraoperative ICG and postoperative DSA to ensure complete obliteration. ${ }^{7,8}$ In some cases, ICG-VA is used as adjunct to intraoperative DSA. However, in developing countries like India, ICG-VA can serve as a useful tool in the armamentarium of neurosurgeons during clipping of aneurysms due to its cost effectiveness and poor follow-up of patients.

\section{Conflict of Interest}

None declared.

\section{References}

1 D'Souza S. Aneurysmal Subarachnoid hemorrhage. J Neurosurg Anesthesiol 2015;27(3):222-240

2 Tajsic T, Cullen J, Guilfoyle M, et al. Indocyanine green fluorescence video angiography reduces vascular injury-related morbidity during micro-neurosurgical clipping of ruptured cerebral aneurysms: a retrospective observational study. Acta Neurochir (Wien) 2019;161(11):2397-2401

3 Yanaka K, Asakawa H, Noguchi S, et al. Intraoperative angiography evaluation of the microsurgical clipping of unruptured cerebral aneurysms. Neurol Med Chir (Tokyo) 2002;42(5): 193-200, discussion 201

4 Raabe A, Beck J, Gerlach R, Zimmermann M, Seifert V. Nearinfrared indocyanine green video angiography: a new method for intraoperative assessment of vascular flow. Neurosurgery 2003;52(1):132-139, discussion 139

5 Feindel W, Yamamoto YL, Hodge P. The human cerebral microcirculation studied by intra-arterial radio-active tracers, Coomassie Blue and fluorescein dyes. Bibl Anat 1967;9:220-224

6 Roessler K, Krawagna M, Dörfler A, Buchfelder M, Ganslandt O. Essentials in intraoperative indocyanine green videoangiography assessment for intracranial aneurysm surgery: conclusions from 295 consecutively clipped aneurysms and review of the literature. Neurosurg Focus 2014;36(2):E7

7 Doss VT, Goyal N, Humphries W, Hoit D, Arthur A, Elijovich L. Comparison of Intraoperative Indocyanine Green Angiography and Digital Subtraction Angiography for Clipping of Intracranial Aneurysms. Intervent Neurol 2015;3(3-4):129-134

8 Riva M, Amin-Hanjani S, Giussani C, De Witte O, Bruneau M. Indocyanine Green Videoangiography in Aneurysm Surgery: Systematic Review and Meta-Analysis. Neurosurgery 2018; 83(2):166-180 